\title{
Ultrastructural observations of the early and late stages of gorgonian coral (Junceella juncea) oocytes
}

\author{
Sujune Tsai ${ }^{d}$, Yating Jhuang ${ }^{b}$, Emma Spikings ${ }^{c}$, Ping-Jyun Sung ${ }^{\mathrm{a}, \mathrm{b}}$, Chiahsin Lin ${ }^{\mathrm{a}, \mathrm{b}, *}$ \\ a National Museum of Marine Biology \& Aquarium, 2 Houwan Road, Checheng, Pingtung, Taiwan, ROC \\ ${ }^{\mathrm{b}}$ Institute of Marine Biotechnology, National Dong Hwa University, 2 Houwan Road, Checheng, Pingtung, Taiwan, ROC \\ c LIRANS Institute of Research in the Applied Natural Sciences, University of Bedfordshire, 250 Butterfield, Great Marlings, Luton, Bedfordshire LU2 8DL, UK \\ d Department of Biotechnology, Mingdao University, 369 Wen-Hua Road, Peetow, Chang Hua 52345, Taiwan, ROC
}

\section{A R T I C L E I N F O}

\section{Article history:}

Received 5 March 2013

Received in revised form 5 November 2013

Accepted 3 May 2014

Available online 9 May 2014

\section{Keywords:}

Gorgonian coral

TEM

Ultrastructure

Yolk formation

Oocyte

\begin{abstract}
A B S T R A C T
The developmental oogenesis of gorgonian coral was investigated at the histological level. The objective of this study was to examine and improve the understanding of Junceella juncea oogenesis using ultrastructural methods, such as histological sectioning and transmission electron microscopy. At least three types of yolk materials were observed in this study: yolk body, lipid granules and cortical alveoli. Some of the complex yolk materials were encompassed by concentric or arched layers of smooth and rough endoplasmic reticulum and the Golgi complex in early stage oocytes. Different types of vesicles were found in both early and late stage oocytes and some granules could be seen inside the empty vesicles. This may be a possible method for elaborating complex yolk materials. Homogeneous yolks from different types of inclusions were abundant and the autosynthesis of yolk may be a major mechanism in $J$. juncea oocytes. This is the first report of the ultrastructural observation of oogenesis in gorgonian coral species using transmission electron microscopy. Our study obtained relatively detailed information at the ultrastructural level, and it provides an overview of the oocyte ultrastucture of the gorgonian coral $J$. juncea.
\end{abstract}

(c) 2014 Elsevier Ltd. All rights reserved.

\section{Introduction}

Coral reefs are immensely beneficial to the environment and the economy by acting as natural barriers for coastal regions (Fernandoa et al., 2008), providing large ecosystems (Hatcher, 1997) and by supplying approximately a billion dollars annually to the global economy (Ammar, 2009). However, elevated ocean temperature and acidity, disease risks, human destruction and pollution have massively damaging effects on coral reefs, and they can take a very long time to recover (Lin et al., 2011). Understanding coral reproduction may elucidate aspects of their reproductive strategies that are related to human and natural disturbances (Rinkevich and Loya, 1979).

The reproductive biology of gorgonian corals is still unclear, although studies have been performed to determine their general biology and population ecology (Brazeau and Lasker, 1990; Ribes et al., 2007; Tsai et al., 2011; Zeevi and Benayahu, 1999).

\footnotetext{
* Corresponding author at: National Museum of Marine Biology \& Aquarium, 2 Houwan Road, Checheng, Pingtung 944, Taiwan, ROC Tel.: +886 88825001\#1356.

E-mail address: chiahsin@nmmba.gov.tw (C. Lin).
}

Numerous studies have described the sexual reproduction of gorgonian corals such as Anthoplexaura dimorpha (Seo et al., 2008) and Plexaura flexuosa (Pakes and Woollacott, 2008) as well as the stony corals Stylophora pistillata (Rinkevich and Loya, 1979), Euphyllia ancora (Shikina et al., 2012), Caulastrea furcate, Lobophyllia corymbosa (Kawaroe et al., 2007) and Mussismilia hispida (Neves and Pires, 2002) and the soft coral Heteroxenia fuscescens (Ben-David-Zaslow et al., 1999; Benayahu et al., 1989). However, these studies focused on the sexuality, reproductive cycle, spawning and colony fecundity of corals, whereas coral developmental oogenesis has been investigated at a histological level (Simpson, 2009). In contrast, ultrastructural investigations of mature eggs have focused on the differentiation and organization of black coral oocytes Cirrhipathes cfr. anguina (Gaino and Scoccia, 2008, 2010).

The effects of environmental and anthropogenic stresses mean that gorgonian corals are undergoing a continuing decline in population size and reproductive ability (Lin et al., 2012; Tsai et al., 2011). At present, no descriptions are available on the process of oocyte development in gorgonian corals based on transmission electron microscopy. Thus, the objective of this study was to enhance the understanding of Junceella juncea oogenesis using histological and ultrastructural methods in order to support various biotechnology 
applications aimed at conservation, including assisted reproduction, propagation and aquaculture of corals.

\section{Materials and methods}

\subsection{Coral collection and identification}

Scuba divers collected $J$. juncea from seaward slopes at a depth below $20 \mathrm{~m}$ in Kenting National Park, Nanwan, Taiwan (the collection request was approved by Kenting National Park Management Office) during June to August in 2010 and 2011. This species is gonochoric and practises internal fertilization. Branches of approximately $50 \mathrm{~cm}$ in length were sampled with scissors from five randomly selected colonies and smaller branches were left in situ to allow their further growth. The cut branches were placed in $200 \mathrm{~L}$ containers with native seawater and transported to the Marine Husbandry Center, National Museum of Marine Biology and Aquarium, which has a continuous seawater flow system that operates at $25^{\circ} \mathrm{C}$. The taxonomic identification of coral species was based on sclerites to distinguish between J.juncea and Ellisella robusta, which are similar in colour (Tsai et al., 2011). The sclerites of both species are double-headed in appearance. However, under a light microscope (C31, Olympus, Japan), the acute tips of the J. juncea sclerites and the blunt tubercules of E. robusta were very distinctive.

\subsection{Oocyte isolation}

A surgical scalpel was used to divide coenchyme from one side of the coral branch tissues into sections of approximately $20 \mathrm{~mm}$. The removed tissues were transferred to a 100 -mm Petri dish containing filtered $(0.4 \mu \mathrm{m})$ natural seawater (35 ppt) and the oocytes were isolated from tissues using forceps and pipette suction under a dissecting microscope (SZ51, Olympus, Japan). The isolated oocytes were then transferred from the Petri dish into six-well cell culture dishes and washed a minimum of three times with filtered natural seawater, before histological sectioning and transmission electron microscopy.

\subsection{Histology}

Histological sectioning of oocytes was performed as described previously by Tsai et al. (2011). In brief, it comprised fixation in formalin, dehydration, infiltration, embedding in paraffin wax, sectioning and staining with Gill 2 haematoxylin and eosin.

\subsection{Transmission electron microscopy}

Transmission electron microscopy was used to determine the ultrastructure of oocytes at different developmental stages. Oocytes were pre-fixed in a solution containing $2.5 \%$ glutaraldehyde, $2 \%$ paraformaldehyde, $0.1 \mathrm{M}$ phosphate buffer and $5 \%$ sucrose for $2 \mathrm{~h}$, before they were post-fixed with $1 \%$ osmium tetroxide solution and stored away from light for $1 \mathrm{~h}$ at $25^{\circ} \mathrm{C}$. After pre- and post-fixation, the oocytes were washed thrice in $0.1 \mathrm{M}$ phosphate buffer and shaken for 20 min using an orbital shaker (Major Science, Taiwan). The oocytes were then dehydrated using a graded series of $50 \%, 70 \%, 80 \%, 90 \%$, $95 \%$ ethanol ( $30 \mathrm{~min}$ ), $100 \%$ ethanol $+100 \%$ acetone $(30 \mathrm{~min} \times 2)$ and $100 \%$ acetone $(30 \mathrm{~min} \times 3)$ at $25^{\circ} \mathrm{C}$. After progressive dehydration, infiltration and embedding were performed by placing the fixed oocytes into plastic moulds via a series of $100 \%$ ethanol $+100 \%$ Spurr's resin $(1: 1,1 \mathrm{~h}), 100 \%$ ethanol $+100 \%$ Spurr's resin $(1: 3,1 \mathrm{~h})$ and $100 \%$ Suprr's resin $(24 \mathrm{~h})$ at $25^{\circ} \mathrm{C}$. The samples were then stored at $60^{\circ} \mathrm{C}$ for $48 \mathrm{~h}$ to allow polymerization. A diamond knife (MS 14410, Diatome, USA) on an autramicrotome (ultracut R, Leica, Germany) was used to slice the polymerized blocks into oocyte sections with a thickness of approximately
$70 \mathrm{~nm}$. The sections were collected using nickel grids and doublestained in $2 \%$ filtered uranyl acetate for $40 \mathrm{~min}$ (stored away from light) and lead citrate (with $10 \mathrm{~N} \mathrm{NaOH}$ ) for $5 \mathrm{~min}$. After each staining procedure, the samples were washed repeatedly thrice in boiled double-distilled $\mathrm{H}_{2} \mathrm{O}$. The samples were then observed using a Hitachi 600 transmission electron microscope (JEM-1400, JEOL, Japan) at an accelerating voltage of $82 \mathrm{kV}$ (filament, $56 \mu \mathrm{A}$ ) and a camera system (Gatan digital micrograph) was used to acquire digital images.

\section{Results}

\subsection{Biological and morphological characteristics of coral oocytes}

According to the light microscopic analysis, J. juncea oocytes were generally spherical in shape (Fig. 1A). The early and late stage oocytes were orange in colour, whereas the later stages were darker (Fig. 1A). Oocytes measuring 50-300 $\mu \mathrm{m}$ in diameter were observed, where the size was related to the developmental stage of maturation. Approximately 6-12 oocytes at different stages were found in a polyp cavity (Fig. $1 \mathrm{~A}-\mathrm{C}$ ), which were connected by the pedicles of their mesenteries (Fig. 1D). The structure of J. juncea comprised a central core, gastrodermis and epidermis (Fig. 1C). Early stage oocytes tended to lie on the primary mesentery regions. Masses of white mesentery material were produced to separate oocytes from one another as well as to expel the oocytes during the final maturation stage (Fig. 1A).

\subsection{Early stage oocytes: vitellogenesis}

The oocytes in this stage attained a diameter of $100-200 \mu \mathrm{m}$, and the nuclei, including the electron-dense nucleolus in the nucleoplasm, ranged from 7 to $15 \mu \mathrm{m}$ (Fig. 2A). Several well-developed pores were visible in the nuclear envelope (Fig. 2B). Mitochondria (with well-formed cristae and matrix, Fig. 2C) were observed in close proximity to the nucleus. The diameters of the lipid granules, yolk bodies and cortical alveoli were readily observed and their ranges were 5-10, 1-2 and 0.1-0.5 $\mu \mathrm{m}$, respectively (Fig. 2D). Yolk body inclusions (Fig. 2E-H) with elongated tubules or small round vesicles produced by Golgi complexes were also found in the oocytes (Fig. 2E and H). The cisternae of the endoplasmic reticulum were observed in close proximity to the nucleus (Fig. 2J), adjacent to Golgi complexes (Fig. 2I). Portions of the endoplasmic reticulum cisternae were divided into small vesicles (Fig. 2J). The intercellular space was increased due to cytoplasm and yolk accumulation, which resulted in darker red oocytes (Fig. 1A). Various cell organelles were dispersed in the cytoplasm, including chromatin, mitochondria and Golgi complexes. The lipid yolk was encompassed by the rough endoplasmic reticulum. The proximity of the rough endoplasmic reticulum to the lipid yolk suggests that it has an important role (Fig. 2J). Certain small yolk bodies were fused to larger ones by Golgi complexes (Fig. 2I). Vesicles of different sizes were observed adjacent to the Golgi complexes (Fig. 2J). Concentric or arched layers of rough endoplasmic reticulum surrounded the granules and vacuoles, and were found in close proximity to the nucleus (Fig. 2K). There were different types of vesicles in the oocytes (Fig. 3). Granules could also be seen inside otherwise empty vesicles (Fig. 3A and B). The most abundant vesicles were small and had the ability to fuse into larger vesicles (Fig. $3 \mathrm{~A}$ and $\mathrm{B}$ ). Certain vesicles contained spotty granular materials (Fig. 3D), whereas others included electron-dense lipids (Fig. 3E). The digestion of bacteria was also evident in the oocytes (Fig. 3C).

In some oocytes, phagocytosis was evident based on the phagolysosomes in close contact with the membranes (Fig. 4A). The phagolysosomes were approximately $10 \mu \mathrm{m}$ in diameter 

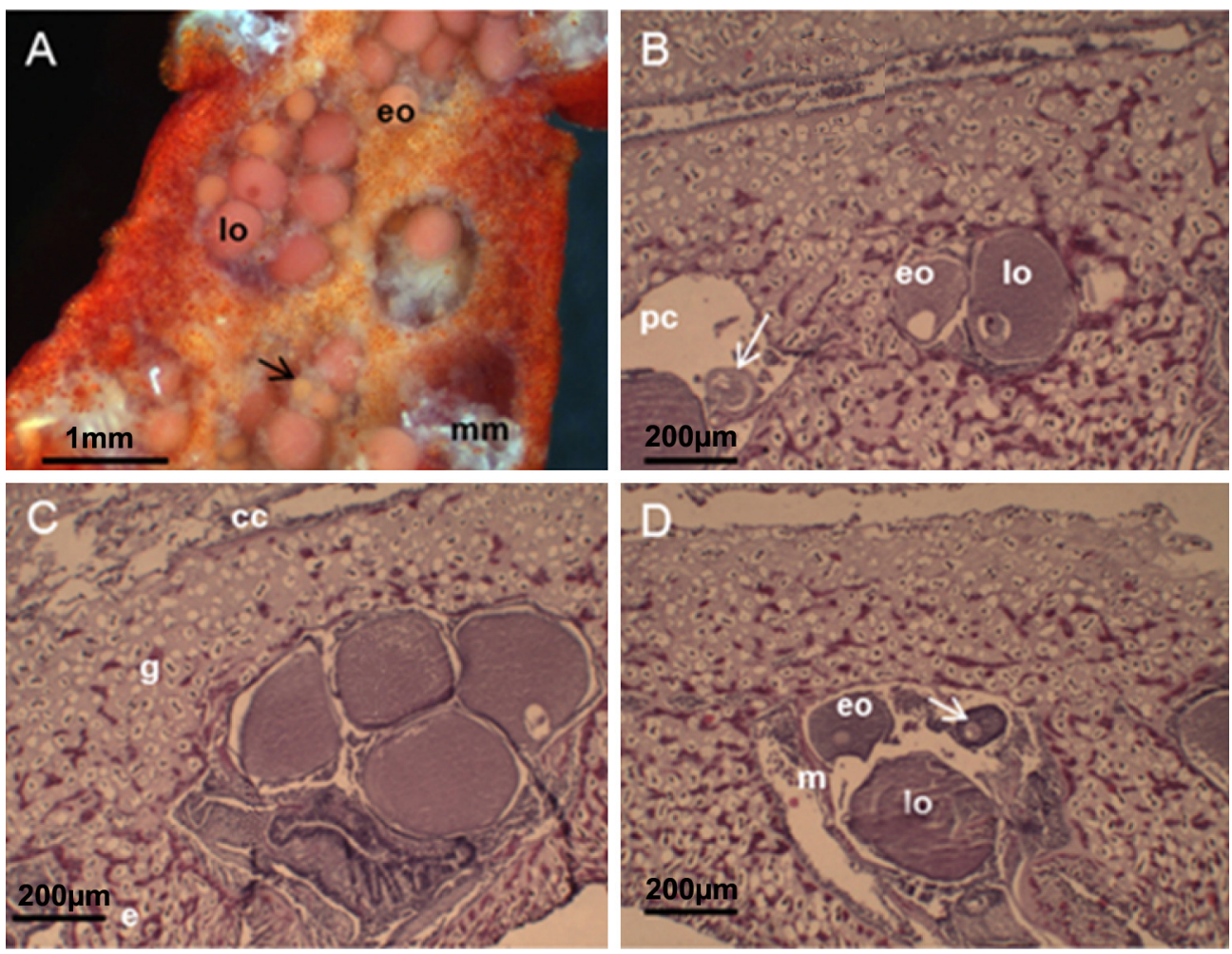

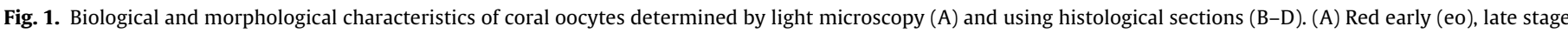

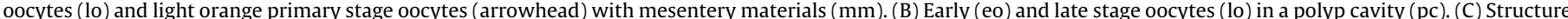

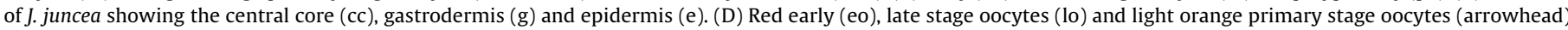

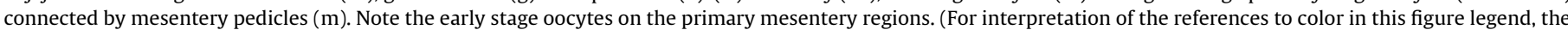
reader is referred to the web version of the article.)

(mean $\pm \mathrm{SD}, n=20$ ) and had heterogeneous inclusions such as lipid granules, vacuoles, vesicles, vitelline platelets and digested bacteria (Fig. 4A). In some cases, they were flattened to initiate phagocytosis. Occasional phagolysosomes were observed in the vitelline coat and were incorporated into pockets within the oocytes (Fig. 4B). Microvilli were often observed between the oocytes and phagolysosomes (Fig. 4C), with microvilli material forming in the cytoplasm (Fig. 4D)

\subsection{Late stage oocytes}

The cytoplasm and nuclei of oocytes increased in size with oocyte development. They had a diameter of 200-350 $\mu \mathrm{m}$ with a mean of $250 \pm 8 \mu \mathrm{m}$ (mean $\pm \mathrm{SD}, n=20$ ). The nuclei diameters were 10-15 $\mu \mathrm{m}$ at the border of the cells as the oocytes reached their final development (Fig. 1). The nuclei changed shape as a result of their attachment to the oocyte membrane. Each oocyte contained up to four nucleoli at this stage (Fig. 5A). Mitochondria (with well-formed cristae and matrix) and vesicles were seen at this stage in proximity to the nucleus (Fig. 5B). The ooplasm contained homogeneous and fine-grained fibres (chromatin).

Numerous granules were observed, which were distributed throughout the oocytes, including lipid granules, yolk bodies and cortical alveoli (Fig. 5C). Throughout this stage, the diameter of these lipid granules, yolk bodies and cortical alveoli increased from $5 \mu \mathrm{m} \pm 1 \mu \mathrm{m}$ (mean $\pm \mathrm{SD}, n=20$ ), $5 \mu \mathrm{m} \pm 1 \mu \mathrm{m}$ (mean \pm SD, $n=20$ ) and $6 \mu \mathrm{m} \pm 1 \mu \mathrm{m}$ (mean $\pm \mathrm{SD}, n=20$ ) at the early stage to $5 \mu \mathrm{m} \pm 1 \mu \mathrm{m}$ (mean \pm SD,$n=20$ ), $5 \mu \mathrm{m} \pm 1 \mu \mathrm{m}$ (mean \pm SD,$n=20$ ) and $6 \mu \mathrm{m} \pm 1 \mu \mathrm{m}$ (mean $\pm \mathrm{SD}, n=20$ ), respectively. During this stage, the cisternae of the rough and smooth endoplasmic reticulum, which were evident in the early stage oocytes, became relatively rare. The vitelline coats were reticulated and had a thickness of $5 \pm 8 \mu \mathrm{m}$ (mean $\pm \mathrm{SD}, n=20$, Fig. 5D). The microvilli were more evident throughout this stage than the previous stages and were not embedded in the vitelline coats (Fig. 5E). Cortical alveoli formed a thin band beneath the microvilli and clustered in the peripheral region (Fig. $5 \mathrm{E}$ ). The vitelline platelets were also observed in oocytes and phagolysosomes (Fig. 6A and B). The structure of the vitelline platelet (carried by phagolysosomes) comprised a central electron-dense core and a transparent envelope. The vitelline platelet had a diameter of $5 \mu \mathrm{m} \pm 1 \mu \mathrm{m}$ (mean \pm SD, $n=20$ ), and the central core was $2-3 \mu \mathrm{m} \pm 1 \mu \mathrm{m}$ (mean $\pm \mathrm{SD}, n=20$ ) in length.

\section{Discussion}

Gaino and Scoccia (2008) demonstrated that the early stage oocytes of the black coral (Cirrhipathes cfr. anguina) were limited to the primary mesenteries against the body wall and pharynx, which was similar to our results. The early stage $J$. juncea oocytes tended to lie on the primary mesentery regions; therefore, it is possible that the eggs may spawn repeatedly in a series. Sewell and Young (1997) suggested that the size and quantity of oocytes are related to reproductive success in marine invertebrates. To transform into planktotrophic larvae, production of a large number of small oocytes was energetically cheap, whereas a small number of high-energy and large oocytes was likely to become lecithotrophic larvae (Sewell and Young, 1997). Larger oocytes also have more efficient chemotaxis (Levitan, 1996). In addition, it has been reported that the size of the oocyte is associated with energy storage, which supports the subsequent oocyte dispersal and embryo development (Seo et al., 2008). The size of mature oocytes varies between coral species. Anthothelidae Tripalea clavaria (Excoffon et al., 2004) and Gorgoniidae 


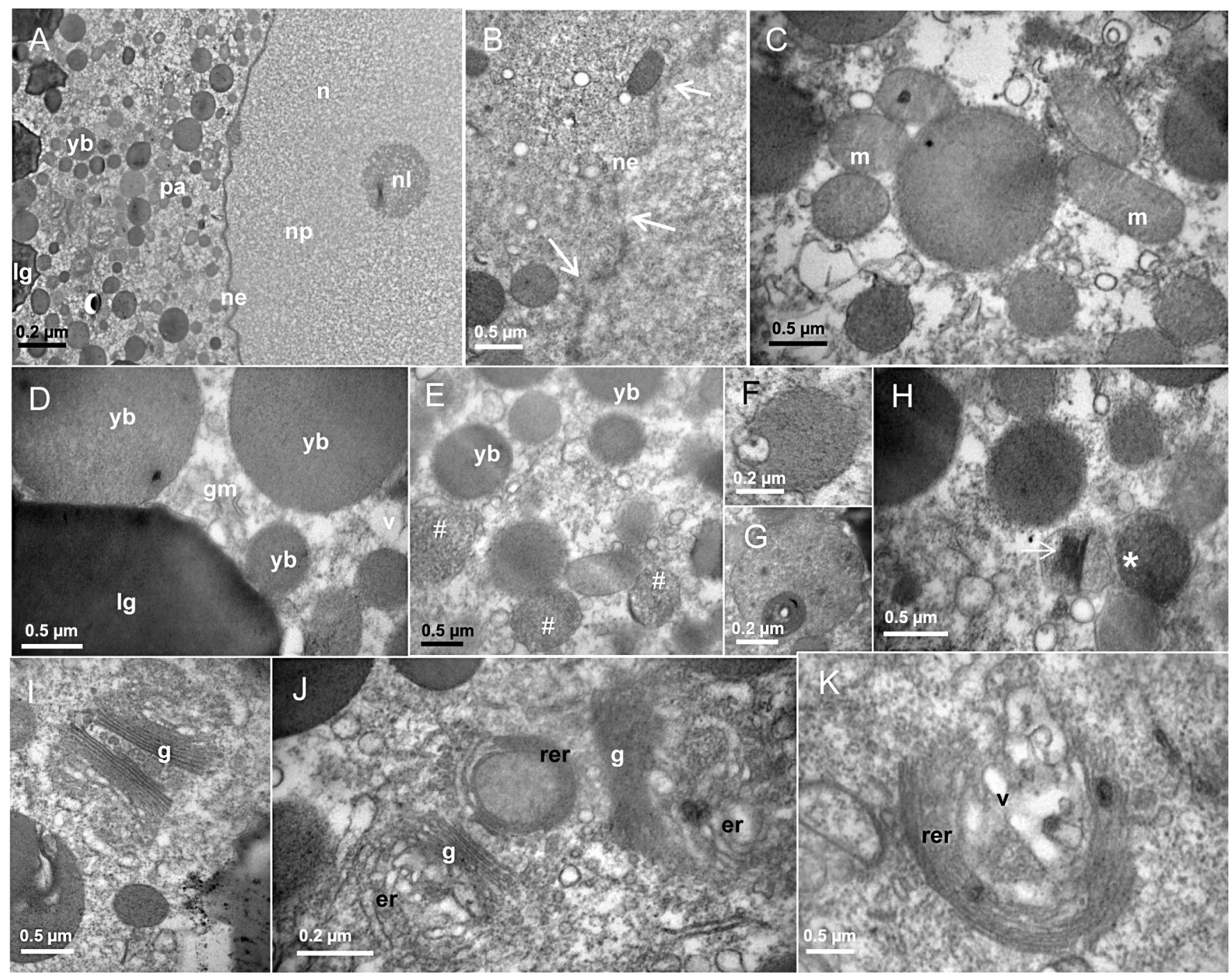

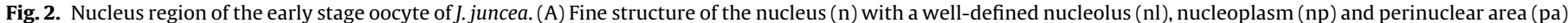

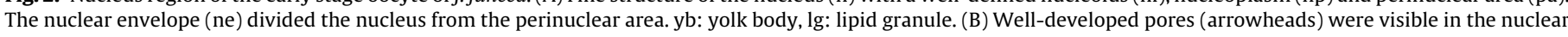

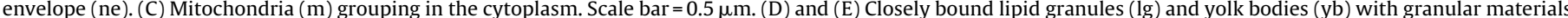

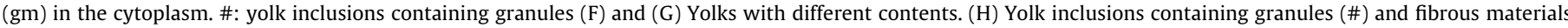

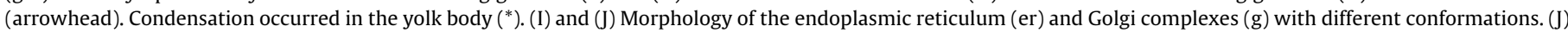
The yolk body encompassed by the rough endoplasmic reticulum (rer). (K) Nascent vesicles (v) produced by the rough endoplasmic reticulum (rer).
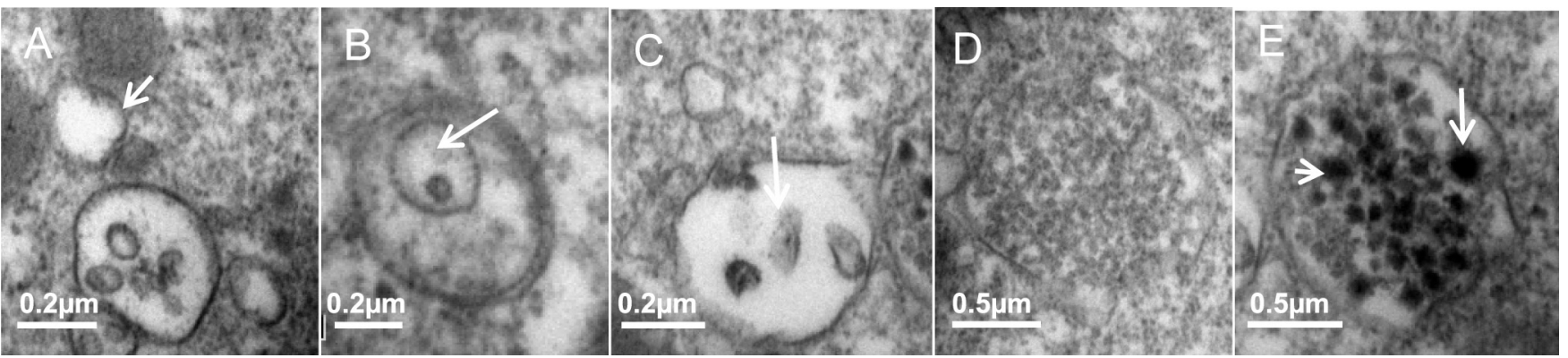

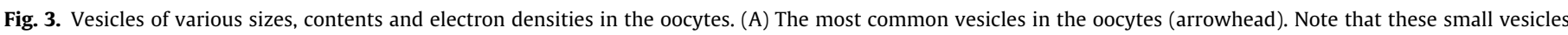

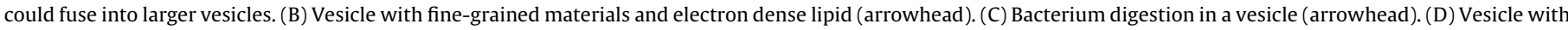
spotty granular substances. (E) Cluster of lipid granules (arrowhead) in a vesicle.

P. flexuosa (Pakes and Woollacott, 2008) have large oocytes of $>500 \mu \mathrm{m}$, whereas smaller oocytes of $<150 \mu \mathrm{m}$ are found in the Pocilloporidae Pocillopora verrucosa and the Agariciidae Pavona varians (Shlesinger et al., 1998). Most coral oocytes measure $150-500 \mu \mathrm{m}$ in diameter, including $J$. juncea. However, no study has reported the correlation between the polyp cavity and oocyte size.

In this study, we observed a large nucleus to cytoplasm ratio, with non-condensed chromatin at the early stage in contrast to the late stage. Each nucleus contained up to four nucleoli in $J$. 


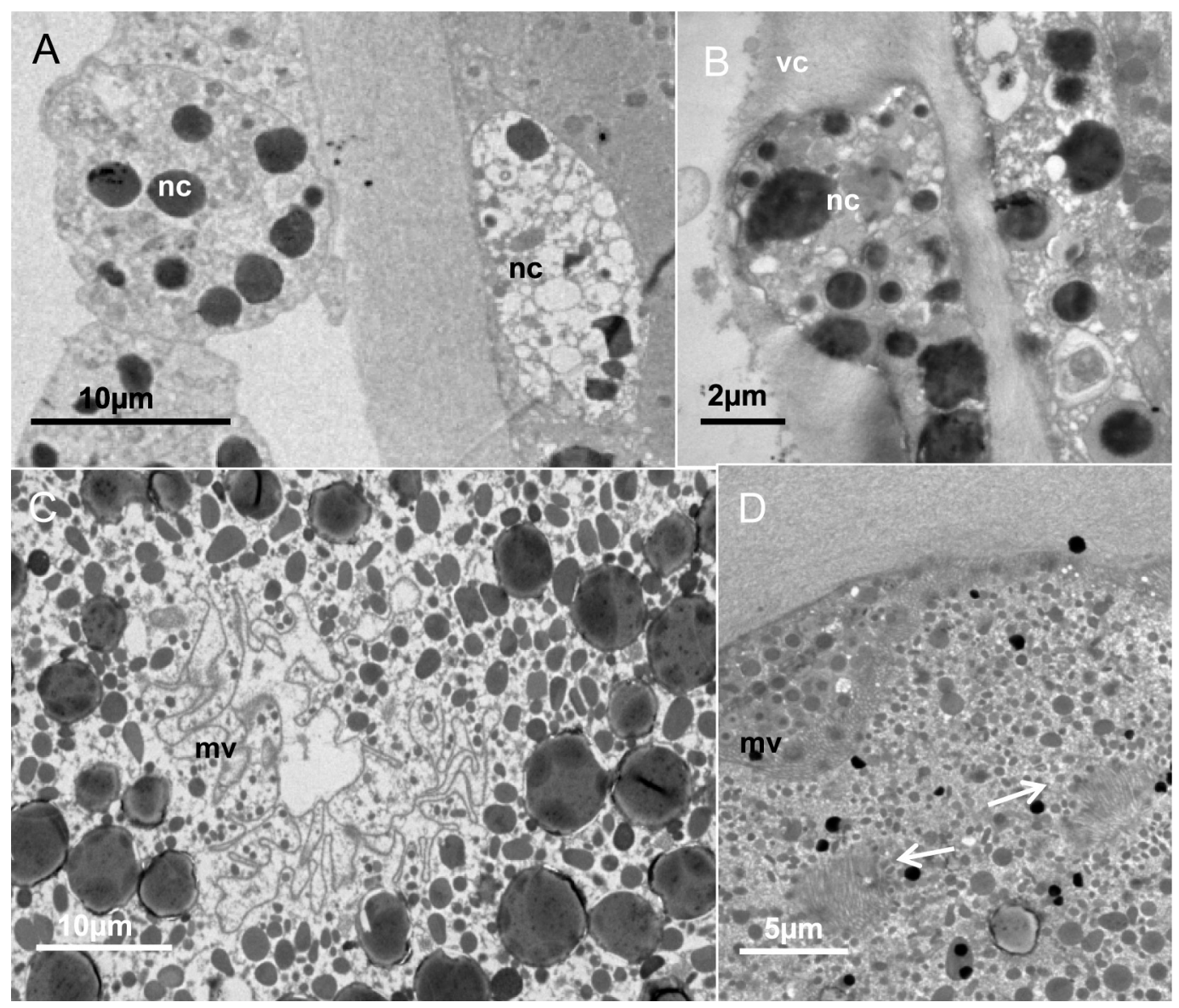

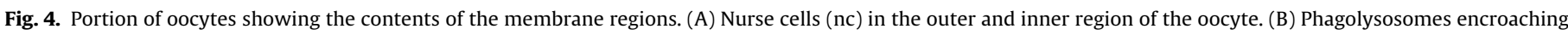

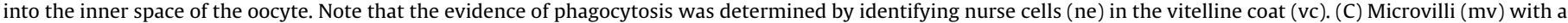
convoluted morphology. (D) Microvilli (mv) materials formed in the cytoplasm (arrowheads).

juncea oocytes, which is similar to amphibians, fish and insects (Vincent et al., 1969). These organisms are considered to have a high level of ribosomal DNA gene amplification compared with uni-nucleolate oocytes such as the mollusc Mulinia lateralis, worm Urechis caupo and starfish Asterias forbesii (Azevedo et al., 1984; Coimbra and Azevedo, 1984; Dawid and Brown, 1970), but the nucleoli of uni- and multi-nucleolate oocytes are important sites for abundant RNA synthesis during oocyte development (Coimbra and Azevedo, 1984). J. juncea oocytes contained well-developed nuclear envelopes, which allowed ribonucleoproteins to be transported out of the nucleus (Amor et al., 2004; Sciscioli et al., 1991; Swenson et al., 1987). Clumped and granular electron-dense materials were found around the outer nuclear envelope in $J$. juncea oocytes. It has been suggested that these granular materials are derived from ribosome-related particles located near the nuclear membrane (Apisawetakan et al., 2001). In the present study, meiotic processes and polar bodies were not identified in early or late stage oocytes. Evidence of meiosis completion includes the observation of a polar body released from the oocyte of a sea anemone Haliplanella lineate, prior to spawning (Fukui, 1991).

Our study demonstrated that the yolk materials occupied the majority of the oocyte, which accounted for the energy reserves rather than buoyancy because J.juncea releases eggs with the ability to settle. At least three types of yolk materials were observed in this study: the yolk body, lipid granules and cortical alveoli. In gonochoric J.juncea, the oocytes and sperm are released separately (Tsai et al., 2011) and the energy reserves of oocytes are important before fertilization. No information is available regarding the elaboration of complex yolk materials in coral oocytes, but evidence has been found in various invertebrate species using transmission electron microscopy. Eckelbarger and Davis (1996) demonstrated that the elaboration of complex yolk materials in molluscan oocytes was homogeneous and involved several organelles such as Golgi bodies, endoplasmic reticulum, rough endoplasmic reticulum, smooth endoplasmic reticulum, mitochondria, autophagous vacuoles and multivesicular bodies. The number of these organelles increased in the cytoplasm of $J$. juncea oocytes, which suggested strong organelle activities and emphasized the importance of organelle activities during vitellogenesis. Some of the complex yolk materials were encompassed by concentric or arched layers of smooth and rough endoplasmic reticulum. The endoplasmic reticulum is a site for yolk material synthesis, before progression to the Golgi for granule development. Low-molecular weight organic compounds (glucose, fatty acids and amino acid) from outside the oocytes supported the yolk elaboration process. Similar types of oocytic development have been found in invertebrates such as the neogastropods Bolinus brandaris (Amor et al., 2004) and Haliotis varia (Najmudeen, 2008) as well as the bivalve Mytilus edulis (Pipe, 1987).

Different types of vesicles were found in the oocytes, and it is possible that these vesicles were nutrient reserves (Larkman, 1984). Granules could also be seen inside empty vesicles. It is possible that these are elaborate complex yolk materials. A previous observation of the electron-dense materials found in vesicles suggested that they may have a secretory activity. The most abundant type was small vesicles with no apparent content. These small vesicles could fuse into larger vesicles that release their proteinaceous contents outside oocytes. According to Rigby (1979), these 


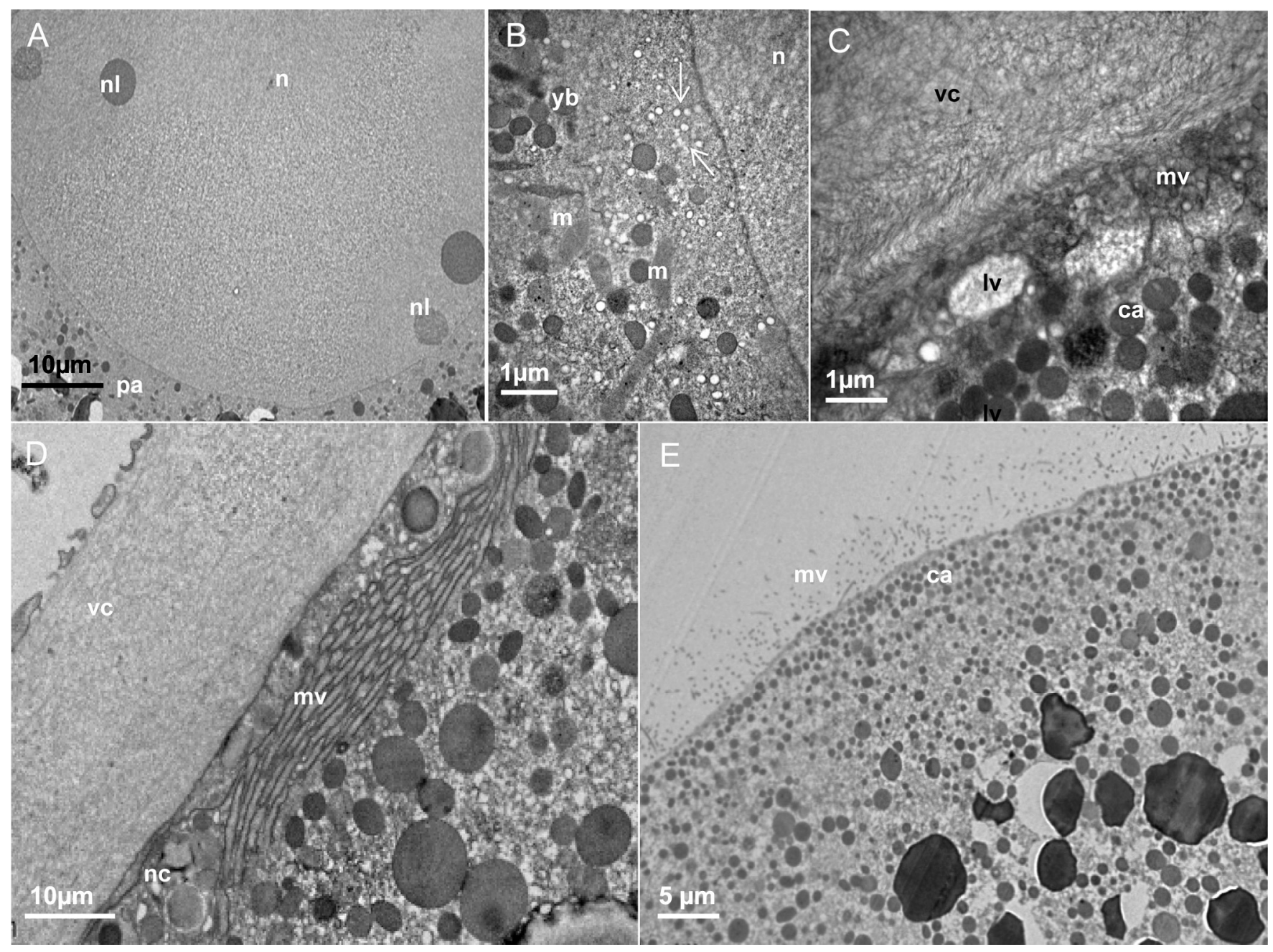

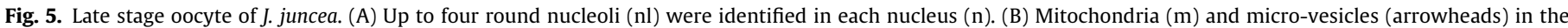

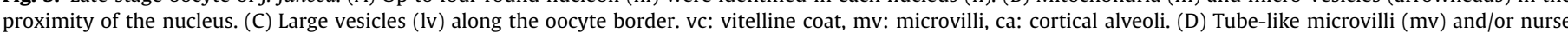

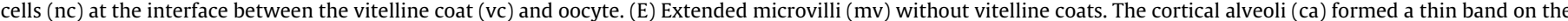
peripheral region of oocytes beneath the microvilli ( $\mathrm{mv}$ ) and oolemma.
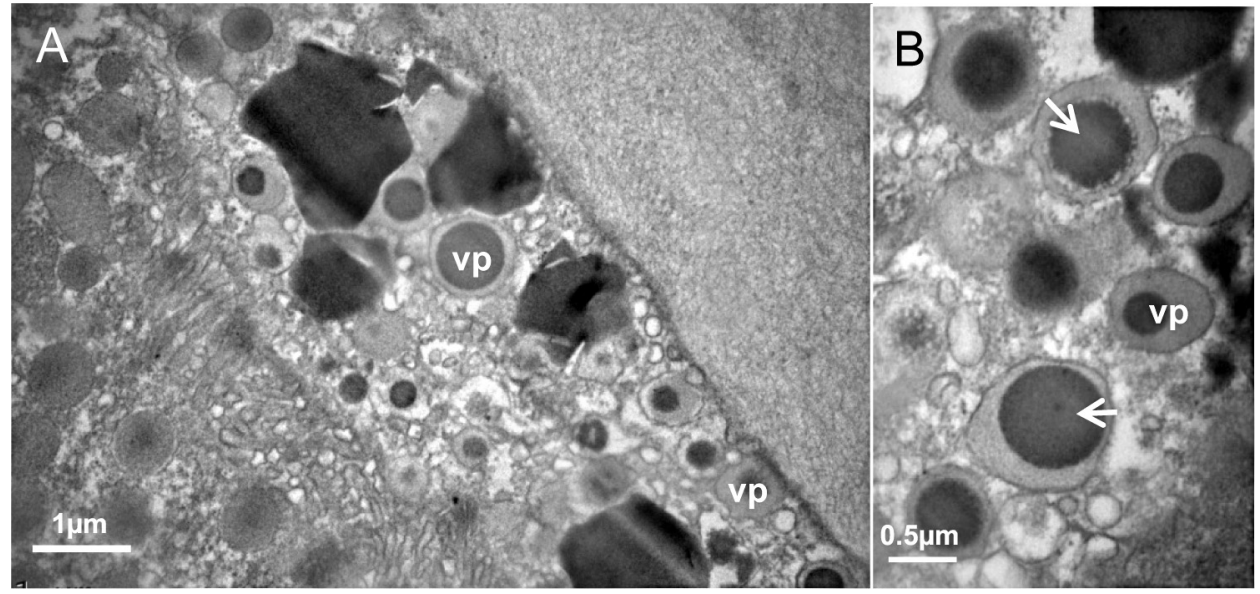

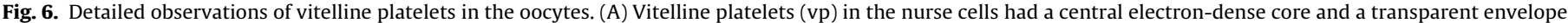
(B) Enlarged view of vitelline platelets (vp) with various forms (arrowheads).

endoplasmic reticulum and Golgi-derived vesicles suggest high levels of proteinaceous and carbohydrate metabolism.

The mechanism of yolk autosynthesis was proposed by Eckelbarger (1994), which is the most primitive method of yolk elaboration in the majority of marine invertebrates. Homogeneous yolks from different types of inclusions were abundant in J. juncea oocytes. Homogeneous and heterogeneous yolks were present simultaneously, which have been reported previously in 
demosponge (Axinella damicornis and Raspaciona aculeata) oocytes (Riesgo and Maldonado, 2009). However, it has been reported that oocytes containing solely heterogeneous yolks were present in some invertebrate species such as polychaetes, echinoderms and molluscs (Anderson, 1974). Unlike other coral species, J.juncea does not require dinoflagellate endosymbionts to obtain nutrients. The elaboration and accumulation of nutritional reserves are the main differences in oocyte development between non-symbiodinium and symbiodinium corals. In the present study, we observed the phagocytosis of complete phagolysosomes with yolk precursors during oocyte development. These phagolysosomes were related to material transfers from the outside to the inside of oocytes, and they have never been reported in other coral species. However, few phagolysosomes were observed in the oocytes. The present data are insufficient evidence to demonstrate that these phagolysosomes generate heterogeneous products in J. juncea oocytes (although we found similar contents in phagolysosomes, such as lipid granules, vesicles and vitelline platelets). Therefore, the auto-synthesis of yolk by homogeneity may be the predominant mechanism in $J$. juncea oocytes. In agreement with a previous report related to the gastropod B. brandaris (Amor et al., 2004), vitelline platelets were also observed in $J$. juncea oocytes. The structure of the vitelline platelet comprised a central electron-dense core and a transparent envelope. The core originated from vitelline material and the transparent envelope was considered to be from the mitochondria (Amor et al., 2004), Golgi body (Hill and Bowen, 1976), or annulate lamellae (Amor et al., 2004). Several forms of vitelline platelets were present in J. juncea oocytes. However, they were carried mainly in nurse cells and a relatively low amount of vitelline platelets was noted in the oocytes. These results were preliminary and it is unclear whether the vitelline platelets in J. juncea oocytes were heterogeneous or homogeneous.

Microvilli may provide some mechanical protection during oocyte development. Very few previous studies of coral species have analyzed microvilli with respect to patterning differences in oocytes (Benayahu et al., 1989; Gaino and Scoccia, 2008, 2010). The structure of the microvilli of J.juncea oocytes has not been reported previously. Tube-like microvilli surrounded the surface, which is similar to other coral species, such as $H$. fuscescen (Benayahu et al., 1989). The oocyte of $H$. fuscescens is covered by a follicular and mesogleal coat. Unlike other invertebrae species (Eckelbarger et al., 1998; Najmudeen, 2008; Rigby, 1979), the microvilli of J. juncea oocytes were not embedded in the vitelline coats. A dense $1-2-\mu \mathrm{m}$ microvilli layer was present on the oocyte surface for protection. Longer microvilli $(10-20 \mu \mathrm{m})$ have been found in some sea anemone oocytes (Larkman and Carter, 1984; Schäifer, 1984). In the present study, reticulated vitelline coats were observed to enclose the oocytes. This type of vitelline coat has also been identified as a cortical reaction in the oocytes of the sea pen Pennatula aculeata (Eckelbarger et al., 1998), abalone H. varia (Najmudeen, 2008) and black coral Myriopathes sp. (Gaino and Scoccia, 2008, 2010). The functions of the vitelline coats are unclear; however, we suggest that it has a similar role to that of microvilli, i.e., nutritional exchange and protection for the early stage oocytes before the microvilli are fully developed. Cortical alveoli formed a thin band beneath the microvilli and clustered at the peripheral region in late stage oocytes. They were produced throughout the cytoplasm during oogenesis, and they migrated to the peripheral region when the oocytes were mature. Finally, the oocytes were released from the corals and the vitelline coats may be separated from the oocyte surface through the colloid osmotic pressure, which is produced by proteins and enzymes in the cortical alveoli (Monroy, 1953). Further studies are required to understand the details of the cortical reaction in J. juncea.

To the best of our knowledge, this is the first report of the ultrastructural observation of oogenesis in a gorgonian coral species using transmission electron microscopy. Several studies have reported the sexual reproduction of various coral species based on conventional histological tissue sections. Our study provides more detailed information at the ultrastructural level as well as an overview of the oocyte ultrastructure during different developmental stages in the gorgonian coral J. juncea. The more sensitive transmission electron microscopy analyses facilitated our highly detailed observations of the oogenesis process.

\section{Acknowledgements}

This research was supported by funds from the National Dong Hwa University (Grant number: T220246609) and National Science Council (NSC 102-2313-B-291-002). The authors are also grateful to Dr. Shao-En Peng and the Instrument Centre at National Museum of Marine Biology and Aquarium for technical and instrumental support of this work.

\section{References}

Ammar, M.S.A., 2009. Coral reef restoration and artificial reef management, future and economic. Open Environ. Eng. J. 2, 37-49.

Amor, M.J., Ramon, M., Durfort, M., 2004. Ultrastructural studies of oogenesis in Bolinus brandaris (Gastropoda: Muricidae). Sci. Mar. 68, 343-353.

Anderson, E., 1974. Comparative aspects of the ultrastructure of the female gamete. Int. Rev. Cytol. 4, 1-70.

Apisawetakan, S., Linthong, V., Wanichanon, C., Panasophonkul, S., 2001. Ultrastructure of female germ cells in Haliotis asinina Linnaeus. Invertebr. Reprod. Dev. 39, 67-79.

Azevedo, C., Castilho, F., Coimbra, A., 1984. Finestructure and cytochemistry of the oocytenucleolus in the mollusk Helcion pellucidus (Prosobranchia). J. Ultrastruct. Res. 89 (1), 1-11.

Benayahu, Y., Berner, T., Achituv, Y., 1989. Development of planulae within a mesogleal coat in the soft coral Heteroxenia fuscescens. Mar. Biol. 100, 203-210.

Ben-David-Zaslow, R., Henning, G., Hofmann, D.K., Benayahu, Y., 1999. Reproduction in the Red Sea soft coral Heteroxenia fuscescens: seasonality and long-term record (1991-1997). Mar. Biol. 133, 553-559.

Brazeau, D.A., Lasker, H.R., 1990. Sexual reproduction and external brooding by the Caribbean gorgonian Briareum asbestinum. Mar. Biol. 104 (3), 465-474.

Coimbra, A., Azevedo, C., 1984. Structure and evolution of the nucleolus during oogenesis. In: Van Blerkmon, J., Motta, P.M. (Eds.), Ultrastructure of Reproduction. Martinus, Nijhoff, Boston, pp. 127-139.

Dawid, I.B., Brown, D.D., 1970. The mitochondrial and ribosomal DNA components of oocytes of Urechis caupo. Dev. Biol. 22 (1), 1-14.

Eckelbarger, K.J., 1994. Diversity of metazoan ovaries and vitellogenic mechanisms: implications for life-history theory. Proc. Biol. Soc. 107, 193-218.

Eckelbarger, K.J., Davis, C.V., 1996. Ultrastructure of the gonad and gametogenesis in the eastern oyster, Crassostrea virginica. I. Ovary and oogenesis. Mar. Biol. 127, 79-87.

Eckelbarger, K.J., Tyler, P.A., Langtonc, R.W., 1998. Gonadal morphology and gametogenesis in the sea pen Pennatula aculeata (Anthozoa: Pennatulacea) from the Gulf of Maine. Mar. Biol. 132, 677-690.

Excoffon, A.C., Acuña, F.H., Zamponi, M.O., Genzano, G.N., 2004. Reproduction of the temperate octocoral Tripalea clavaria (Octocorallia: Anthothelidae) from sublittoral outcrops off Mar del Plata, Argentina. J. Mar. Biol. Assoc., UK 84, 695-699.

Fernandoa, H.J.S., Samarawickramab, S.P., Balasubramaniana, S., Hettiarachchib, S.S.L., Voropayeva, S., 2008. Effects of porous barriers such as coral reefs on coastal wave propagation. J. Hydro-environ. Res. 1 (3-4), 187-194.

Fukui, Y., 1991. Embryonic and larval development of the sea anemone Haliplanellu lineara from Japan. Hydrobiologiu 216-217, 137-142.

Gaino, E., Scoccia, F., 2008. Female gametes of the black coral Cirrhipathes cfr. anguina (Anthozoa, Antipatharia) from the Indonesian Marine Park of Bunaken. Invertebr. Reprod. Dev. 51 (3), 119-126.

Gaino, E., Scoccia, F., 2010. Ultrastructural investigation of the sexual reproduction of some members of the black coral: a review. In: Méndez-Vilas, A., Díaz, J. (Eds.), Microscopy: Science, Technology, Applications and Education. , pp. 936-945.

Hatcher, B.G., 1997. Coral reef ecosystems: how much is the whole greater than a sum of the parts? Coral Reefs 16, 77-91.

Hill, R.S., Bowen, I.D., 1976. Studies on the ovotestis of the slug Agriolimax reticulatus (Müller). Cell Tissue Res. 173, 465-482.

Kawaroe, M., Soedharma, D., Maulinia, M., 2007. Oogenesis Karang Sclerectinia Caulastrea furcata dan Lobophyllia corymbosa. J. Biosci. 14 (1), 31-35.

Larkman, A.U., 1984. The fine structure of the mitochondria and the mitochondrial cloud during oogenesis on the sea anemone Actinia. Tissue Cell 16, 393-404.

Larkman, A.U., Carter, M.A., 1984. The apparent absence of a cortical reaction after fertilization in a sea anemone. Tissue Cell 16, 125-130.

Levitan, D.R., 1996. Predicting optimal and unique egg sizes in free spawning marine invertebrates. Am. Nat. 148 (1), 174-188.

Lin, C., Zhang, T., Kuo, F.W., Tsai, S., 2011. Studies on oocytes chilling sensitivity in the context of ATP response of two gorgonian coral species (Junceella juncea and Junceella fragilis). CryoLetters 32, 141-147. 
Lin, C., Wang, L.H. Fan, T.Y., Kuo, F.W., 2012. Lipid content and composition during the oocyte development of two gorgonian coral species in relation to low temperature preservation. PLoS ONE 7 (7), e38689, http://dx.doi.org/10.1371/journal.pone.0038689.

Monroy, A., 1953. A model for the cortical reaction of fertilization in the sea-urchin egg. Cell Mol. Life. Sci. 9 (11), 424-425.

Najmudeen, T.M., 2008. Ultrastructural studies of oogenesis in the variable abalone Haliotis varia (Vetigastropoda: Haliotidae). Aquat. Biol. 2, 143-151.

Neves, E.G., Pires, D.O., 2002. Sexual reproduction of Brazilian coral Mussismilia hispid. (Verrill, 1902). Coral Reefs 21, 161-168.

Pakes, M.J., Woollacott, R.M., 2008. Reproduction of the gorgonian Plexaura flexuosa in Bermuda. J. Exp. Mar. Biol. 357, 121-127.

Pipe, R.K., 1987. Oogenesis in the marine mussel Mytilus edulis: an ultrastructural study. Mar. Biol. 95, 405-414.

Ribes, M., Coma, R., Rossi, S., Micheli, M., 2007. Cycle of gonadal development in Eunicella singularis (Cnidaria: Octocorallia): trends in sexual reproduction in gorgonians. Invertebr. Biol. 126 (4), 307-317.

Riesgo, A., Maldonado, M., 2009. Ultrastructure of oogenesis of two oviparous demosponges: Axinella damicornis and Raspaciona aculeata (Porifera). Tissue Cell 41, 51-65.

Rigby, J.E., 1979. The fine structure of the oocyte and follicle cells of Lymnaea stagnalis, with special reference to the nutrition of the oocyte. Malacologia 18 (1-2), 377-380.

Rinkevich, B., Loya, Y., 1979. The reproduction of the Red Sea coral Stylophora pistillata I. Gonads and Planulae. Mar. Ecol. Prog. Ser. 1, 133-144.

Schäifer, W., 1984. Fortpflanzung und Entwicklung von Anemonia sulcata (Anthozoa, Actiniaria). I. Fortpflanzungszyklus und Struktur der Oocyten vor und nach der Besamung. Helgol/inder. Meersunters. 38, 135-148.
Sciscioli, M., Scalera, S., Liaci, L., Leporo, E., Gherardi, M., Simpson, T.L., 1991. Ultrastructural study of the mature eggs of the marine sponge Strelletta grubii (Porifera Demospongiae). Mol. Reprod. Dev. 28, 346-350.

Seo, S.Y., Hwang, S.J., Song, J.I., 2008. Sexual Reproduction of Anthoplexaura dimorpha (Gorgonacea: Octocorallia) from Munseom, Jejudo Islands, Korea. Anim. Cells Syst. 12 (4), 231-240.

Sewell, M.A., Young, C.M., 1997. Are echinoderm egg size distributions bimodal? Biol. Bull. 193, 297-305.

Shikina, S., Chen, C.J., Liou, J.Y., Shao, Z.F., Chung, Y.J., Lee, Y.H., Chang, C.F., 2012. Germ cell development in the scleractinian coral Euphyllia ancora (Cnidaria, Anthozoa). PLoS ONE 7 (7), e41569, http://dx.doi.org/10.1371/journal.pone.0041569.

Shlesinger, Y., Goulet, T.L., Loya, Y., 1998. Reproductive patterns of scleractinian corals in the northern Red Sea. Mar. Biol. 132, 691-701.

Simpson, A., 2009. Reproduction in octocorals (subclass Octocorallia): a review of published literature. Version 16 July 2009. In Deep-Sea Corals Portal, http://www.ucs.louisiana.edu/ scf4101/Bambooweb/

Swenson, K.I., Borgese, N., Pietrini, G., Ruderman, J.V., 1987. Three translationally regulated mRNAs are stored in the cytoplasm of clam oocytes. Dev. Biol. 123, $10-16$.

Tsai, S., Spikings, E., Haung, I.C., Lin, C., 2011. Study on the mitochondrial activity and membrane potential after exposing later stage oocytes of two gorgonian corals (Junceella juncea and Junceella fragilis) to cryoprotectants. CryoLetters 32 $1-12$.

Vincent, W.S., Halvorson, H.O., Chen, H.R., Shin, D., 1969. A comparison of ribosomal gene amplification in uni- and multinucleolate oocytes. Exp. Cell Res. 57 (2) 240-250.

Zeevi, D., Benayahu, Y., 1999. The gorgonian coral Acabaria biserialis: life history of a successful colonizer of artificial substrata. Mar. Biol. 135, 473-481. 